Article

\title{
Social Protection Implementation Issues in Ethiopia: Client Households' Perceived Enablers and Constrainers of the Productive Safety Net Program
}

\author{
Melisew Dejene Lemma ${ }^{1,2, *}$ and Logan Cochrane ${ }^{1,3}$ \\ 1 Institute of Policy of \& Development Research, Hawassa University, P.O. Box 1558, Hawassa, Ethiopia; \\ logan.cochrane@gmail.com \\ 2 Department of Journalism \& Communication, Hawassa University, P.O. Box 1558, Hawassa, Ethiopia \\ 3 Global and International Studies, Carleton University, Ottawa, ON K1S 5B6, Canada \\ * Correspondence: melisew@hu.edu.et
}

Received: 30 May 2020; Accepted: 12 September 2020; Published: 16 September 2020

\begin{abstract}
Social protection programs need to be suited to the specific context within which they are implemented. To minimize barriers and constraints in implementation, program design needs to integrate and respond to the views of client households and potential beneficiaries, ideally with on-going feedback mechanisms to better respond both to constrainers and to enablers. In order to provide evidence regarding constrainers and enablers in Ethiopia's safety net program, we conducted a household survey to assess policy-backed efforts for social protection service delivery. This paper outlines client households' perceived enablers and constrainers regarding the implementing of the Productive Safety Net Program, Africa's second largest safety net. The findings suggest that client households have identified enablers and constrainers from their lived experience that could be used as a feedback mechanism and as input for future program design. The findings could foster better outcomes in program implementation.
\end{abstract}

Keywords: social protection; Ethiopia; program implementation; enablers; constrainers; client households

\section{Introduction}

Social protection programs are increasingly being funded and implemented in Sub-Saharan Africa, especially after the turn of the millennium. Most of the social transfer programs in Sub-Saharan Africa are non-contributory in modality, being financed by taxes and development assistance [1]. Alongside their funding and implementation, social protection programs in Sub-Saharan Africa have increasingly been subject to research [2]. Garcia and Moore [3], for example, assessed over 120 cash transfer programs in operation between 2000 and 2009. Differing from initiatives in the past, often carried out on an ad hoc nature as emergency response, social protection programs offer regular and predictable services. Moreover, some African countries have integrated such programs into their national social safety net system. Sometimes the programs are granted and protected within regimes of rights [4]. The broadening of social protection programs is a response to the failure of the emergency aid approach that helped in curbing famine but failed to contribute to household food security and poverty alleviation [3]. Hickey et al. [1] describe the development of social transfer programs in Sub-Saharan Africa as a dramatic shift with widespread consequences. Emerging social protection programs are diverse, involving a range of populations in society. When scaled to the national level, these programs require substantial financial investment. Africa has the highest coverage of social assistance programs with an estimated expenditure reaching $4 \%$ of GDP [1]. While social protection has been important in preventing emergency situations and addressing specific concerns, such as school dropout [3], 
Africa's social protection coverage in terms of social insurance and labor protection is generally low. With the rise of inequalities around the world [5], social assistance programs have the potential to minimize these widening divides. As noted by Samson et al., "social transfers not only tackle income poverty; they also provide effective support for broader developmental objectives" [6] (p. 1). However, the role of individuals and communities in designing, implementing, monitoring, evaluating, and adapting social protection, which could be vital for enabling better outcomes, is under-researched [3] (p. 9). Hence, studying the implementation of these expanding social service programs with a focus on the perspectives of the client community and recipient households may help to promote informed decision-making throughout the program cycle-from design to execution.

Investigating implementation issues of social protection programs within their specific context is necessary. Previous research [7] has suggested that there was no universal blueprint for an effective or efficient implementation or service delivery approach. Implementation could be impacted by various issues of the policy cycle, from design to service delivery. Implementation-related challenges outlined by earlier observations include fragmented programs, challenges in policy operationalization, limitations in institutional capacity, the absence of national level registry and/or MIS (Management Information System), resource constraints, the lack of a working grievance management and handling system, and issues of targeting, especially in pastoral areas [4]. Political interference by lower level administration (Kebele administrators) has been among the challenges that affected program implementation in the Ethiopian Productive Safety Net Program (PSNP) [8-10]. This study provides insights on policy-backed efforts for social protection and clients' perceived enablers and constrainers of a social protection program in an African setting. To such end, we explore the views of the clients of the Ethiopian PSNP to learn their perceived enablers and constrainers of program implementation. By enablers, we mean issues that facilitate or promote better implementation outcomes, and by constrainers, we refer to factors that impede effective program implementation.

Designing feasible social transfer programs and their effective implementation requires the understanding of key issues. These include policy priorities, poverty profile, government capacity, and available resources. Scanning the policy priorities would help to identify the kind of public support available to mobilize the political will for effective social protection service provision. Understanding the poverty profile along demographic and spatial lines also paves the way for effective implementation by targeting the right clients of a social protection scheme. The administrative capacity of the government, in terms of previous experience-especially with respect to leadership capacity-would provide a picture as to what kind of program the government could administer. Research indicates that this may require exploring diverse options or the creation of a partnership to strengthen public institutions or find suitable alternatives [7]. Moreover, a rough inventory of the resources available informs the capacity of government and the political commitment in that regard. It also provides details regarding the availability of public or donor resources, as well as the challenges of relying on donors [7].

The implementation of a social protection program is determined by the commitment of the political elite, the availability of reliable information management systems, a pragmatic mix of centralized and decentralized administration, transparent and responsive communication, and an appellate system, as well as the periodic capacity to build implementers, among other factors [7]. What seems less considered in previous research is integrating the perspectives of clients of a program to improve the design and delivery. With this in mind, we explore policy-backed efforts and clients' perceived enablers and constrainers of program implementation of the PSNP in Ethiopia. The following section outlines the methods utilized, after which we present the contextual background regarding the country, the relevant policies, and the PSNP. After presenting the Findings of the paper in Section 4, we offer a discussion of the results and the insights they offer for broader questions.

\section{Materials and Methods}

We pooled data at the household level from client households of the PSNP Public Works component. The PSNP is the second largest social protection program in Sub-Saharan Africa. We adopted stratified 
random sampling using the formula developed by Krejcie and Morgan [11] to draw a representative sample and collected data from 386 households from two areas, Sidama and Hadiya, and within those areas two Woredas/Districts: Boricha and Shashego, respectively. The study covered two Woredas/Districts and four randomly selected kebeles (the lowest level of political administration in Ethiopia), two from each Woreda/District. The study areas of Sidama and Hadiya were purposively selected, as were the Woredas/Districts within them. The kebeles were randomly selected. Based on the sampling frame and the Food Security Desks of the respective Woredas under study, we determined that $32 \%$ of the PSNP client households of Boricha and 33\% of Shashego were female-headed. Hence, we stratified the sample into male-headed and female-headed households and randomly drew a proportionate sample of male-headed and female-headed households, to have their voices properly represented.

We collected data after piloting the survey instrument on client households, equivalent to $2 \%$ of the study sample. The piloting was aimed at validating the instrument. The data collection involved eight enumerators who were trained for this purpose. All the enumerators were able to speak the specific languages of the study communities. We tested the pilot data for reliability and internal consistency of the scales employed. The reliability test for the "perceived enablers", as portrayed in Table 1 of the Results section, was recorded at ( $\alpha$ alpha $\}=0.8)$, and that of the "perceived constrainers" at $(\alpha\{$ alpha $\}=0.95)$.

We included two scales to measure clients' perceived enablers and constrainers of implementation (effective social protection service delivery) in the social protection program they are a part of. The scale to measure perceived "enablers" has a set of six 5-point Likert scale questions with responses ranging from Strongly Agree to Strongly Disagree. These were (1) Effectively targeting the poor that deserve to be clients of the program, (2) Un-delayed/on-time transfer of payments, (3) Strong institutional capacity to facilitate the logistics, transfers, and activities for the PSNP-PWs programs, (4) Coordination and synergy among actors facilitating the PSNP-PWs program, (5) Designing programs that add value (in terms of assets) to the community (assets like roads, ponds, and other relevant facilities), and (6) Designing activities that could diversify the livelihoods of the clients of the program. The perceived "constrainers" scale also included six variables. These were: (1) Lack of capacity of the officers/facilitators of the program, (2) Delayed transfers of benefits/payments, (3) Lack of coordination among actors, (4) Lack of transparency and fairness during targeting, (5) Weak institutional arrangements and capacity, and (6) Dependency attitude among the clients. We developed these scales based on existing literature on related subjects (see [1,2,4,6,7,9]).

We used SPSS version 20 for encoding and analyzing the data. We held a reliability analysis for both of the scales before further analysis. Both of the scales proved statistically sound for further analysis, with details provided in the Results section. We also analyzed available documents and literature to explore the incumbent social protection policy of Ethiopia, with the aim of assessing the government's promises and efforts in establishing social protection programs. The study proposal was reviewed and approved by the Institute of Policy \& Development Research (IPDR) of Hawassa University (Ethiopia). A consent form was read out to each of the client households of the PSNP-PWs who participated in the household survey before data collection by the enumerators. All of the participants of the survey consented to participate in the study.

The study has methodological limitations, as the two study areas (Sidama and Hadiya) and the Woredas/Districts (Boricha and Shashego) were purposively selected. These two study areas were purposively selected for two reasons. First, the researchers had established a trusting relationship with the communities in these regions, which allowed for improved data accuracy, research and experience, and a more in-depth understanding of the context. In addition, both of the study areas are food insecure, identified as Woredas/Districts for PSNP targeting (not all Districts in Ethiopia are covered), with a significant proportion of households included in these Woredas/Districts by the PSNP. To reduce selection bias within these areas, however, we randomly selected the kebeles under study and employed stratified random sampling to select client households. 
Table 1. Public Works Clients' View of Enablers of Effective Service Delivery.

\begin{tabular}{|c|c|c|c|c|c|c|}
\hline \multirow{2}{*}{ Enablers as Viewed by Clients } & \multirow{2}{*}{$\mathbf{N}$} & \multirow{2}{*}{ Mean } & \multirow{2}{*}{ SD } & \multirow{2}{*}{$\mathbf{t}$} & \multicolumn{2}{|c|}{ 95\% C.I. } \\
\hline & & & & & Lower & Upper \\
\hline $\begin{array}{l}\text { Effectively targeting clients who deserve to } \\
\text { be part of the program }\end{array}$ & 389 & 4.41 & 0.53 & $163.08^{* * *}$ & 4.36 & 4.46 \\
\hline Un-delayed/on-time transfer of payments & 389 & 4.06 & 1.18 & $67.77^{* * *}$ & 3.94 & 4.17 \\
\hline $\begin{array}{l}\text { Strong institutional capacity (logistics, } \\
\text { transfers, and activities) }\end{array}$ & 389 & 4.31 & 0.6 & $140.57^{* * *}$ & 4.25 & 4.37 \\
\hline $\begin{array}{c}\text { Coordination and synergy among actors } \\
\text { facilitating program }\end{array}$ & 389 & 4.2 & 0.61 & $136.02 * * *$ & 4.13 & 4.26 \\
\hline $\begin{array}{l}\text { Designing programs that add value (in terms } \\
\text { of assets) to the community (assets like } \\
\text { roads, ponds, and other relevant facilities) }\end{array}$ & 389 & 4.28 & 0.49 & $172.93^{* * *}$ & 4.23 & 4.33 \\
\hline $\begin{array}{l}\text { Designing activities that could diversify the } \\
\text { livelihoods of the clients of the program }\end{array}$ & 389 & 4.23 & 0.58 & $143.73^{* * *}$ & 4.17 & 4.28 \\
\hline
\end{tabular}

\section{Context of the Study}

\subsection{Social Protection Efforts during the EPDRF Regime in Ethiopia}

The implementation of social protection services needs to be based on a sense of ownership by the target community. Neubourg [12] opines that poorer countries face challenges in this regard. Community ownership of such programs is vital for their successful implementation by overcoming corruption and ensuring the efficient use of funds. Neubourg [12] suggests involving community elders in the implementation process to draw upon their knowledge of the social fabric at the local level. According to him, "if decisions are made locally, then they are seen as being more legitimate by the community that stands to benefit from the program than if decisions had been made at central level" [12] (p. 13). Neubourg [12], however, pointed out that the technical capacity at the local level may be a hurdle unless boosted by training and supervision. Barrientos [13] concurs with this assertion when he argues that limitations in implementation capacity at a multitude of points in the policy cycle, from design to service provision, have been a barrier in the Global South. For this and concomitant resource limitations, transforming time-bound programs into sustainable institutions would be a challenge.

The present EPRDF-led (Ethiopian People Revolutionary Democratic Front) government, which has recently evolved into the Prosperity Party (PP), has reached out to donors to implement social protection programs, especially since early 2000s. The PSNP is one of such programs, having emerged as a multi-donor investment [14]. Rahmato [15] argues that a significant amount of investment has been deployed for decades to tackle the food security problem in Ethiopia, with donors contributing more than six billion dollars. Rahmato argues that while some achievements have been made, the issue of food security remains a problem for a sizable portion of both the rural and urban people.

The Central Statistical Agency of Ethiopia conducted a national level Welfare Monitoring Survey that aimed to document the distribution of poverty and income inequality and to gauge the living situation of the people and the impact of various public policies and programs. Adopting household and individual living situations as a measure, it pooled data employing basic life indicators like education, health, childcare, housing, and household assets, among others. The proportion of the population living under absolute poverty decreased from 44 percent in 1999/2000 to 39 percent in 
2004/2005 and to 29 percent in 2010/11 [16]. A significant proportion of the population still experiences poverty. A recent survey estimated the proportion of people living under poverty to be $23.6 \%$ [17].

Recurrent droughts and consequent food insecurity continue to be a challenge for the Government of Ethiopia. For instance, in 1999/2000 drought-induced crop failures affected nearly 10 million people, who required relief assistance. In 2003 another catastrophe affected 14 million people (slightly above one in five people, or $22 \%$ of the population) [18] (p. 28-29). In the 2003 drought, the most fertile areas in the highlands and southern parts of the country were impacted [19]. Consequently, food and non-food assistance was estimated at over U.S. $\$ 85$ million for 2004 alone [18] (p. 32). In its disaster risk management policy, the Government of Ethiopia claimed it has established a better early warning and disaster risk management system [20]. However, with the need of relief being recurrent and their expenses costly, consultations between the international community and the Ethiopian government gave birth to the PSNP, which was launched in 2005 [14]. After that, however, droughts (e.g., in 2008, 2015, 2016, 2017, and 2018) left many millions of Ethiopians without food and reliant upon emergency relief [21]. The New York Times [22], with reference to a government announcement, reported that around 8.2 million people needed food assistance in 2015 alone.

Regarding policy instruments, the government introduced the Developmental Welfare policy in 1996, with provisions targeting children, women, the elderly, and people with disabilities. This policy, which had been in effect for nearly two decades, was replaced by a new social protection policy in 2014 . The reasons that led to the promulgation of the new policy and the difference between the two policy regimes are beyond the scope of this study. For our purposes, in the following section we present an overview of the incumbent social protection policy.

\subsection{The National Social Protection Policy Regime of Ethiopia (2014 to Present)}

The current social protection policy of Ethiopia was debated and discussed for years before it was signed by the legislatures. It got legislative approval in November 2014, though the Ministry of Labor and Social Affairs (MoLSA) released its final draft in early 2012. The policy document draws upon data from the national poverty assessment and welfare monitoring surveys regarding the poverty head count ratio, poverty gap, income inequality, food poverty head count, food poverty gap, food severity, child welfare, (un) (under) employment and the labor market situation, and the disability context. The document seemed to locate poverty within a multidimensional frame (see [23]).

The social protection policy builds upon the national and international policy context for social service provisions. It specifically bases itself on Article $41 \mathrm{sub} 5-7$, Article 90, Article 25, and Article 35 of the constitution, that call upon the state to address social problems, expand jobs and facilitate job opportunities, facilitate basic service provision, and ensure equity and equality among its citizens. The policy document cites legal instruments including the family code, the labor proclamation, and proclamations of social insurance (public and private), among others. It also adheres to international instruments like the Universal Declaration of Human Rights, the Convention on the Rights of the Child (UNCRC), the Beijing Declaration (Elimination of all forms of discrimination against women), the African Charter on the Rights and Welfare of the child, and the ILO Declaration on Fundamental Principles and Rights at Work. The social protection policy also reviews social protection efforts in the country. Among others, the policy cites the social insurance program, food security interventions, basic social service provision, the national insurance program, supports for vulnerable children, the state of health insurance, disaster risk management, the situation of support for people with disabilities, provisions for the elderly, efforts in employment promotion, and community-based social support. It reviewed these documents to identify gaps in social protection service provision and measures needed along that line.

The national social protection policy document outlined three major gaps for social service provision in the Ethiopian context. These include: policy gaps, program planning and implementation gaps, and the institutional arrangement and capacity. The major policy gap as identified in the policy document is the fragmented policy efforts regarding a multitude of social issues which had not been 
united within a comprehensive social protection frame. Major limitations of the program design and implementation, as identified in the policy document, include the lack of implementation standards and the lack or limited public participation, from program inception through design to monitoring and evaluation.

The implementation and institutional gaps outlined in the policy document include: knowledge gaps regarding the purpose of social protection on the legal and socio-economic fronts; gaps in legal authority as to who should enforce the law for a wider and multi-sectoral implementation of social protection; gaps in vertical and horizontal interfaces between and among stakeholders in social protection; capacity limitations of government bureaucracy involved in social protection service provision and the consequent constraints in the effective design and efficient implementation of interventions [7]. The gaps in both vertical and horizontal interfaces suggest the limitations of involving client communities/households in program design and implementation.

The national social protection policy document envisioned "to see all Ethiopians enjoy social and economic well-being, security and social justice" [23] (p. 14). It had set six objectives:

i. Protect poor and vulnerable individuals, households, and communities from the adverse effects of shocks and destitution;

ii. Increase the scope of social insurance;

iii. Increase access to equitable and quality health, education, and social welfare services to build human capital, thus breaking the intergenerational transmission of poverty;

iv. Guarantee a minimum level of employment for the long-term unemployed and under-employed;

v. Enhance the social status and progressively realize the social and economic rights of the excluded and marginalized;

vi. Ensure that the different levels of society are taking appropriate responsibility for the implementation of social protection policy [23] (p. 15).

The document also formulated four focus areas the policy intended to address: social safety nets, livelihood and employment schemes, social insurance, and addressing inequalities of access to basic services.

\subsection{The Productive Safety Net Program as an Instrument of Social Protection}

The origin of the PSNP is associated with the 2002/03 drought, that affected nearly 13 million people and put them in a situation wherein they required emergency food aid. Early initiatives (in the 1990s and early 2000s), though succeeding in preventing famine, failed to address the structural roots of vulnerability. To address this, the PSNP was launched in 2005 by the Government of Ethiopia, with the support of international partners [14]. The Productive Safety Net Program (PSNP) was established with three-pronged purposes. These included: "smoothing food consumption" for the chronically food-insecure rural poor, through cash or food transfer during "hunger season" ("protection from hunger"); "protecting household assets" by cushioning asset depletion due to food insecurity ("preventive"); "building community assets" ("promotive") through the public works program that usually focused on building village and feeder roads [24] (p. 4). The food-for-work modality has been operational for a relatively longer time, as it had been used by the previous regime (1974-1991). Food-for-work, however, has been criticized, as participants were not able to accumulate assets [24]. The perspective of success or otherwise depends on which of the purposes are focused upon (protection, prevention, promotion). Focusing upon protection and prevention, a 2014 World Bank assessment on safety net programs in 22 countries praised the flexibility of the PSNP to respond to shocks and crises [4]. Success also depends on scale; in Reinert's [25] view, addressing crises is one thing and building an economy that could resist crises another.

The PSNP targeted the food-insecure and vulnerable public, providing them with a public work opportunity for up to five days within a week "during the agricultural slack season." [26] (p. 119). The basic assumption behind the PSNP is that, provided with such opportunities, people can escape 
chronic poverty, as they would not be forced to sell their "productive assets". Moreover, the public work endeavor also creates community assets, as people are engaged in constructing rural village roads $[24,27,28]$. Hence, the safety net scheme is in a position to fill in gaps that were not addressed by the overall macroeconomic platform, which is sometimes referred to as market failure.

The PSNP aimed to enable Ethiopia to overcome the need for annual emergency food aid. It was a major commitment and investment, with an annual operational cost of 500 million USD [26,29]. Given the country's drought-prone, rain-fed agricultural system, the safety net scheme hoped to salvage the "able-bodied" from falling a prey to the "dependency syndrome" [24]. The shift was grounded in the assumption that "cash transfers rather than food aid, with predictable multi-annual transfers [are] expected to lead to 'graduation' within a defined time period" [24] (p. 1). Provisions for those involved in the program amounted to $30 \mathrm{birr}$ (US\$1.70), which was later adjusted to $50 \mathrm{birr}$ (US\$2.80) or $15 \mathrm{~kg}$ of grain [28] for five days' labor work. In capability terms, the following question ought to be asked: what can one buy for this money? For critics like Reinert, the problem lies in the agricultural system itself and economic policies that could put a viable agricultural sector in place. One long-term option here could be irrigation, given the country's rich water resources and large tracts of arable land. In Reinert's view [25], donors could help in such structural investment, and a living lesson in History is the Marshall Plan, which transformed the production system of Germany, especially its manufacturing sector.

According to Devereux et al. [30], the PSNP targeted vulnerable and poorer groups with limited access to land and those who barely have productive assets and were impoverished. The other wing of the PSNP— the direct support modality—involves recipients who are unable to work (e.g., due to disability or age) or should not work in burdensome manual labor (e.g., expecting mothers). Devereux et al. [30] reported improvements in living conditions by program participants compared to their non-participating counterparts and "that cash payments were used for a far wider range of purposes than food payments were" (p. 121). Sabates-Wheeler and Devereux [31], based on the regression results of their study, maintain that due to the escalating inflation in Ethiopia since 2007, in-kind transfers (food transfers) and cash and food provisions were having a better impact compared to cash transfers alone. They observed a better asset accumulation and "self-reported food security" due to cash plus food schemes.

Based on panel data from three surveys conducted between 2002 and 2007, a study by Andersson, Alemu, and Stage [26] maintains that though the long-term impact of the PSNP is too early to forecast, they found no evidence that suggests improvements of livestock holdings by program participants contrary to the program's goal. In the Ethiopian PSNP, a household moves out of the program when it is believed to be "food self-sufficient". In the past, such people would get further support from the OFSP (Other Food Security Program), aimed at enabling them to build assets and protecting them from "dropping into food insecurity again" [28] (p. 7). This support is now provided through the livelihood promotion component of the PSNP.

Research indicates that the cash transfer of the PSNP helped participants "to reduce food consumption deficits in their families, as well as investing in farming, small enterprises and education of their children" [24] (p. 11). However, Devereux and Guenthe [24] argue that the impacts of such investments were subject to the "depth of poverty" and food insecurity by the respective households and relative to "the small level and disbursement of PSNP transfers" [24] (p. 11). Hoddinot et al. [32] (p. 761) found that participants involved in the PSNP (receiving "high" level cash disbursement) and the OFSP/HABP showed "considerable improvements in the use of fertilizer and enhanced investments in agriculture likely to improve agricultural productivity". They also found, however, that "high levels of participation in the PSNP Program alone had no effect on agricultural input use or productivity and limited impact on agricultural investments" [32]. A study by Andersson, Alemu, and Stage [26] (p. 125) attributed improvement in forestry activity to the PSNP and improvements in household livestock holdings to the OFSP. The empirical literature here concurs with Reinert [25], to whom safety nets alone are not able to address the structural causes of poverty. However, they help the poor to get out of destitution (the protective and preventative purposes of the PSNP). What is lacking in the 
Ethiopian PSNP, however, is the skills development aspect, equipping the participants with livelihood diversifying skills (through trainings, for instance), in order to enhance the promotive purpose.

According to Pankhurst and Rahmato [33], PSNP beneficiaries in rural Ethiopia are estimated at 8.3 million, with 319 food insecure woredas covered by the program. The PSNP issues, according to van Uffelen [34] (p. 26), are:

"the capacity to implement safety nets (including issues of targeting and the inclusion of labour short household), selection of the resource transfer type, the importance to look beyond economic impact and consider the social dimension of safety, alignment of formal with informal forms of social assistance provision, and the need for transparency and accountability of formal social protection initiatives".

Based on his field study in Ebinat woreda of the Amhara region, Aschale [35] reported that 37 percent of the rural population were beneficiaries of the PSNP, in the form of food and/or cash transfer. According to him, 91 percent of the communities participated in the public works, in the food-for-work modality. The findings from his study [35], however, suggested that "only a few households reported a positive impact in terms of livelihood improvement and long-term household food security" (p. 453).

\section{Results of the Study}

A set of five-point Likert scale questions were presented to PSNP-PW's client households in the household survey to understand and assess their views on enablers (factors the household clients view as promoting effective implementation) and constrainers (issues that impede implementation) of delivery-based social protection services, based on their experience on the ground. We analyze the results of that survey in the two following sub-sections. The results are presented below, covering enablers and constrainers, respectively.

\subsection{Clients' View of Enablers of Service Delivery in PSNP in Southern Ethiopia}

A set of six questions were presented under "enablers of effective service delivery", with responses labeled as $5=$ Strongly agree, $4=$ Agree, $3=$ No Opinion, $2=$ Disagree and $1=$ Strongly Disagree.

As shown in Table 1, the findings indicate that the majority of the respondents agreed that effective targeting of the deserving poor is one of the enablers of effective social protection service delivery (Mean $=4.41$, Std. Dev $=0.53, \mathrm{CFI}=95 \%$ ). Previous studies indicated that the PSNP had limitations and experienced irregularities in targeting client households [8-10]. There were reports of instances where political motivations intervened in client recruitment [8]. Respondents also viewed un-delayed/on-time transfer of payments as one of the enablers of effective social protection service delivery (Mean $=4.06$, Std. Dev $=1.18, C F I=95 \%$ ). Delayed transfer induced a further vulnerability of client households to informal loan arrangements with loan sharks with high interest rates. The result of such occurrences led client households to spend their transfers on debt-servicing [21].

The study participants were also of the opinion that "a strong institutional capacity to facilitate the logistics, transfers and activities for the PSNP-PWs program" is an enabler of effective service delivery (Mean $=4.31$, Std. Dev $=0.60, \mathrm{CFI}=95 \%$ ). This is in line with the findings of a previous study that identified gaps in institutional capacity to deliver social protection at the local level [9]. Coordination and synergy among actors facilitating the PSNP-PWs program were also rated as enablers of effective service delivery (Mean $=4.20$, Std. Dev $=0.61, \mathrm{CFI}=95 \%$ ). Limitations in synergy among actors, as reflected in a lack of policy coherence, is an issue in the Ethiopian social protection system [36]. The respondents also suggested that designing programs that add value (in terms of assets) to the community (assets like roads, ponds, and other relevant facilities) can act as an enabler of effective service delivery (Mean $=4.28$, Std. Dev $=0.49, \mathrm{CFI}=95 \%$ ). The study participants also rated "designing activities that could diversify the livelihoods of the clients of the program" as an enabler for effective service delivery (Mean $=4.23$, Std. Dev $=0.58, \mathrm{CFI}=95 \%$ ). This finding agrees with previous findings 
that suggest PSNP client households were not able to accumulate assets in a way that had a meaningful impact in their lives [10].

Respondents were asked to rank the six "enablers" in order of importance, from the most important to the least important. Their rankings are presented in Table 2, below.

Table 2. Respondents' Ranking of "Enablers" of Social Protection Service Delivery.

\begin{tabular}{cc}
\hline Perceived Enabler & PSNP Clients' Ranking of Importance \\
\hline Un-delayed transfer of payment & 1 \\
\hline Designing programs that add value to the community & 2 \\
\hline Coordination and synergy among actors & 3 \\
\hline Strong institutional capacity & 4 \\
\hline Effectively targeting the deserving poor & 5 \\
\hline Designing activities that diversify livelihoods & 6 \\
\hline
\end{tabular}

As shown in Table 2, timely or un-delayed transfer of payment was rated the foremost enabler of program success, as viewed by PSNP-PW's clients. Designing programs that add value to the community was rated the second greatest enabler by PSNP-PW's clients. "Coordination and synergy among actors" was rated the third enabler by the majority of respondents, followed by "strong institutional capacity" and then "effectively targeting the deserving poor". The issue that was rated as the least important enabler, among these options, by PSNP-PW's client households was "designing activities that diversify livelihoods". The identification of delayed transfers as being particularly problematic is not a theoretical issue for PSNP participants. PSNP transfers were delayed for three months, on average, in some areas in Southern Ethiopia [21].

\subsection{Clients' View of Constrainers of Service Delivery in PSNP in Southern Ethiopia}

A set of six five-point Likert scale questions were presented to the respondents under "constrainers of effective service delivery".

As shown in Table 3, the majority of respondents agreed that delayed transfers of benefits/payments are one of the constrainers of effective service delivery (Mean $=4.31$, Std. Dev $=0.74, \mathrm{CFI}=95 \%$ ). A delay of PSNP transfers for several months was witnessed by several studies conducted in different parts of Ethiopia $[9,13,21]$. PSNP Public Works client households were also of the opinion that the "lack of coordination among actors" is a constrainer of effective service delivery (Mean = 3.98, Std. Dev $=1.13$, CFI $=95 \%$ ). "Lack of capacity of the officers/facilitators of the program" was also rated as constrainer of effective service delivery (Mean $=3.95, \mathrm{SD}=1.17, \mathrm{CFI}=95 \%$ ). These issues manifest themselves in delayed service delivery, as in delayed transfers. The respondents also identified the "lack of transparency and fairness during targeting" as constrainer of effective service delivery. This is in line with the findings of previous studies of the PSNP at the kebele level [8,10]. The participants of the household survey also viewed "weak institutional arrangements and capacity" as a constrainer of effective service delivery (Mean $=3.95$, Std. Dev $=1.12$, CFI $=95 \%$ ). Logistic arrangements and lack of coordination among actors were observed as institutional challenges at the woreda level [9]. The majority of the respondents agreed that a "dependency attitude among the clients" could be a constrainer of effective service delivery (Mean $=3.89$, Std. Dev $=1.14, \mathrm{CFI}=95 \%$ ). 
Table 3. Public Works Clients' View of Constrainers of Effective Service Delivery.

\begin{tabular}{|c|c|c|c|c|c|c|}
\hline \multirow{2}{*}{ Constrainers as viewed by Clients } & \multirow{2}{*}{$\mathbf{N}$} & \multirow{2}{*}{ Mean } & \multirow{2}{*}{ SD } & \multirow{2}{*}{$\mathbf{t}$} & \multicolumn{2}{|c|}{ 95\% C.I. } \\
\hline & & & & & Lower & Upper \\
\hline $\begin{array}{c}\text { Lack of capacity of the officers/facilitators of } \\
\text { the program }\end{array}$ & 389 & 3.95 & 1.17 & $66.34^{* * *}$ & 3.83 & 4.06 \\
\hline Delayed transfers of benefits/payments & 389 & 4.31 & 0.74 & $114.38^{* * *}$ & 4.24 & 4.39 \\
\hline Lack of coordination among actors & 389 & 3.98 & 1.13 & $69.33^{* * *}$ & 3.86 & 4.09 \\
\hline $\begin{array}{c}\text { Lack of transparency and fairness during } \\
\text { targeting }\end{array}$ & 389 & 3.95 & 1.08 & $72.19^{* * *}$ & 3.84 & 4.05 \\
\hline $\begin{array}{l}\text { Weak institutional arrangements and } \\
\text { capacity }\end{array}$ & 389 & 3.95 & 1.12 & $69.73^{* * *}$ & 3.84 & 4.05 \\
\hline Dependency attitude among the clients & 389 & 3.89 & 1.14 & $67.21^{* * *}$ & 3.77 & 4.00 \\
\hline
\end{tabular}

\section{Discussion}

Understanding the enablers and constrainers of a program's effectiveness as viewed by clients is vital to better recognize the priorities and overcome the bottlenecks of service delivery. The social protection efforts by the Government of Ethiopia have been encouraging, especially since the establishment of the PSNP, in the early 2000s. The social protection policy that came into effect in November 2014 signaled the government's interest and recognition of these issues, which need to be realized in the lives of people. The capacity to implement such programs is an important constituent in gauging the impact and usefulness of social protection programs. In line with this, Hoddinott et al. [9] (p. 216) write that "impact is mediated by the capacity to implement". As the findings of this study suggest, capacity limitations are constraining the potential impact of the PSNP. The capacity to implement the program is compromised by delayed payment transfers to client households, with the majority of the study participants rating timely transfers as the foremost important "enabler".

The study findings indicated that designing programs that "add value to the community" was crucial, and rated this task as the second most important "enabler". Cochrane and Tamiru [8] contend that communities were not substantially involved in the design of the program manual, nor do some implementing staff have sufficient training on how to effectively incorporate participatory planning. In a nation-wide survey, Berhanne et al. [10] support this assertion and point out that the participation of the community in the PSNP was limited. Hoddinott et al. [9] investigated the development capacity of the PSNP from the perspective of implementing a food security program with a focus on Woredas' capacity to execute the payment system, the performance of the food security task force, community involvement in targeting, and the workings of the appellate system when complaints arise. They blamed institutional arrangements, among others.

The study findings suggest that "coordination and synergy among actors" is crucial for effective social protection service delivery, being rated as the third most important enabler by the majority of respondents. This is in line with the findings of a study by Dejene and Cochrane [36] that revealed a lack of coherence between policies and the consequent failure in concerted synergy among actors of social protection in Ethiopia. Client households" view of "coordination and synergy among actors" as an important enabler reflects these broader assessments. In this regard, Hoddinott et al. [9] suggested that Woredas executing the PSNP were under-resourced. However, the study also helps locate the constraints: officers working for the PSNP (both full-time and part-time) were educated, and most implementers were trained. There were frequent incidents in some regions of delayed payments due 
to the lengthy communication process between regional, woreda, and kebele hierarchies. There was also a lack of access of vehicles in some areas to remote communities. On a broader systemic level, the early warning capacity at the woreda level was low due to understaffing, which resulted in delayed responses, with the assistance arriving after the community members had adopted negative coping strategies. The accessibility of the community food security task force (CFSTF) or the contacts between the community and the CFSTF decreased between 2008 and 2010 (compared to 2006 and 2008), resulting in a decline in households' ability to identify the roles of the CFSTF. This decline was particularly high among female-headed households. Dejene [21] argues that this might be due to the ad hoc arrangement of the CFSTF, being done mostly on a voluntary basis. According to Hoddinott et al. [9], the involvement of the community in targeting clients and the selection process were absent in some areas.

The findings of this study indicate that installing a pertinent payment modality that enables on-time delivery of transfers is a top priority for the client households, as the majority of them perceive "un-delayed payment transfer" as an enabler. Dejene [21] contends that delayed payment was a big issue, as client households and other stakeholders of the PSNP in southern Ethiopia reported a three-month delay, on average. The situation pushed food-insecure clients into a poverty trap by compromising their protection, as they had to use their transfers to cover the costs of loan-servicing (loans being granted informally by loan sharks when transfers did not arrive on time). Clients obtained loans at unconventional and unusually high interest rate arrangements [21]. While interest rates from these informal sources are high, so too are rates from formal credit providers, but the latter present additional barriers to access as well as risks in the case of default [37]. The clients in the communities where this study took place put the blame on the payment arrangement through Omo Microfinance Institute (OMFI), a government affiliate that introduced a mobile-network-based payment system. Limited network coverage in some areas in rural southern Ethiopia presented challenges for the implementation of the system.

As the study findings have suggested, targeting the deserving poor is vital for effective service delivery in a social protection system. However, other studies have found that "there were instances of favoritism and nepotism by elites at the community level" [9] (p. 202). This evidence is consistent with the findings of Cochrane and Tamiru [8], who identified injustices against the client community by some kebele elites. According to Hoddinott et al. [9], the appeals system is in place but it use by the community varied from one area to another. Berhane et al. [10] agree with these findings, especially when it comes to identifying the appeals system as being ineffective. Berhane et al. [10] associated implementation problems with a lack of technical capacity, supervision challenges, and delayed transfer of budget for capital projects. As for Cochrane and Tamiru [8], they found that in some communities the majority of the provisions of the manual were unimplemented. Based on their interviews with community members, Cochrane and Tamiru [8] (p. 658) argue that community members rebuffed the idea, stating that clients had "no option or right to complain". Cochrane and Tamiru identify the overlapping responsibilities of the political apparatus at the lowest administrative level for political administration and execution of the social protection program. This, according to Cochrane and Tamiru [8] (p. 657), enabled power and politics to actively engage with social service provision, resulting in sidelining and excluding political dissent from the food security program. The study by Hoddinott et al. [9], however, noted improvements in service delivery, program design, and administrative capacity compared to the early years of the program's inception. They argued that the findings are "a positive story that highlights the importance of investments in program inputs and institutional structure", equally highlighting the importance of improvements in on-time payment, accumulating woreda and kebele level poverty data for objective targeting of "the poor". A shared belief by both clients and implementers was the issue of delayed payment seriously affecting both the implementation and the impact that should have occurred due to the program (pp. 214-215). 


\section{Conclusions}

Government efforts to improve social protection service delivery, as reflected in the incumbent comprehensive social protection policy and in the installment of the PSNP as a social protection program in many parts of rural Ethiopia, have been commendable. However, designing programs that improve the livelihood situation of clients and the community at large requires the integration of the understanding and views of the clients and potential clients of social protection programs. Designing programs that improve the livelihood situation of the target clients needs to involve the community for at least three reasons: first, it helps programs to look beyond their life cycle with regard to facilitating a sustainable livelihood for clients; second, to enable a sense of ownership among the community and thereby pave the way for a better program implementation; third, individuals have the right to participate in programs implemented in their communities. This study outlined client households" perceived "enablers" and "constrainers" in implementing a social protection service delivery. The perceived "enablers" and "constrainers" identified based on the clients' lived experience could serve as input for future revisions and show how feedback mechanisms are important components for program design, not only to better fulfill the specific contextual needs but also to promote ownership and protect rights. In the next phase, the PSNP or other similar programs in sub-Saharan Africa need to consult with their target community and potential clients to establish effective programs and ensure that on-going feedback mechanisms are integrated and allow for on-going improvement.

Author Contributions: M.D.L. collected field data under the supervision of L.C. drafted an outline which was revised and edited by L.C., M.D.L. drafted the introduction and methods and L.C. reviewed and made technical and content editions. Both authors contributed to the analysis and the conclusion sections. All authors have read and agreed to the published version of the manuscript.

Funding: This research received no external funding.

Conflicts of Interest: The authors declare no conflict of interest.

\section{References}

1. Hickey, S.; Lovers, T.; Nino-Zarazua, M.; Seekings, J. The Negotiated Politics of Social Protection in East and Southwestern Africa. In The Politics of Social Protection in Easter and Southern Africa; Hickey, S., Lovers, T., Nino-Zarazua, M., Seekings, J., Eds.; Oxford University Press: Oxford, UK, 2020; pp. 1-41.

2. Niño-Zarazúaetal, M.; Barrientos, A.; Hickey, S.; Hulme, D. Social Protection in Sub-Saharan Africa: Getting the Politics Right. In World Development; Elsevier: Amsterdam, The Netherlands, 2012; Volume 40, pp. 163-176.

3. Garcia, M.; Moore, C.M.T. The Cash Dividend: The Rise of Cash Transfer Programs in Sub-Saharan Africa. In Directions in Development; Human Development; World Bank: Washington, DC, USA, 2012; Available online: https://openknowledge.worldbank.org/handle/10986/2246License:CCBY3.0IGO (accessed on 20 December 2018).

4. Monchuk, V. Reducing Poverty and Investing in People: The New Role of Safety Nets in Africa; The World Bank: Washington, DC, USA, 2014.

5. UNDP. Beyond income, beyond averages, beyond today: Inequalities in human development in the 21st century. In Human Development Report 2019; The United Nations Development Program: New York, NY, USA, 2019.

6. Samson, M.; van Niekerk, I.; Mac Quene, K. Designing and Implementing Social Transfer Programmes; EPRI Press: Cape Town, South Africa, 2010.

7. Samson, M.; van Niekerk, I.; Mac Quene, K. Designing and Implementing Social Transfer Programs; Economic Policy Research Institute: Cape Town, South Africa, 2006.

8. Cochrane, L.; Tamiru, Y. Ethiopia's Productive Safety Net Program: Power, Politics, and Practice. J. Int. Dev. 2016, 28, 649-665. [CrossRef]

9. Hoddinot, J.; Sabates-Wheeler, R.; Berhane, G.; Handino, M.; Kumar, N.; Lind, J.; Tafesse, A.; Tefera, M. Implementing Large Scale Food Security Programs in Rural Ethiopia: Insights from the Productive Safety Net Program. In Food Security, Safety Nets and Social Protection in Ethiopia; Dessalegn, R., Pankhurst, A., van Uffelen, J.-G., Eds.; Forum for Social Studies: Addis Ababa, Ethiopia, 2013; pp. 175-217. 
10. Berhane, G.; Hoddinot, J.; Kumar, N.; Tafesse, A.S. The impact of Ethiopia's Productive Safety Nets and Household Asset Building Program: 2006-2010; IFPRI: Washington, DC, USA, 2011.

11. Krejcie, R.V.; Morgan, D.W. Determining Sample Size for Research Activities. Educ. Psychol. Manag. 1970, 30, 607-610. [CrossRef]

12. Neubourg, C. Incentives and the Role of Institutions in the Provision of Social Safety Nets. In SP Discussion Paper; No. 0226-25300; World Bank Institute: Washington, DC, USA, 2002.

13. Barrientos, A. Social Protection and Poverty. Int. J. Soc. Welf. 2011, 20, 240-249. [CrossRef]

14. Knippenberg, E.; Hoddinott, J. Shocks, Social Protection, and Resilience: Evidence from Ethiopia; Working Paper 109; IFPRI: Washington, DC, USA, 2017.

15. Rahmato, D. Food Security and Safety Nets: Assessment \& Challenges. In Food Security, Safety Nets and Social Protection in Ethiopia; Dessalegn, R., Pankhurst, A., van Uffelen, J.-G., Eds.; Forum for Social Studies: Addis Ababa, Ethiopia, 2013; pp. 113-146.

16. CSA. Welfare Monitoring Survey 2011: Statistical Report Basic Population Characteristics, Education, Health, Child Care and Breast Feeding; CSA: Addis Ababa, Ethiopia, 2012.

17. National Planning Commission. Growth and Transformation Plan (GTP) of the Federal Democratic Republic of Ethiopia (2015/16-2019/20); NPC: Addis Ababa, Ethiopia, 2016.

18. Kiros, F.G. Enough with Famines in Ethiopia: A Clarion Call; Commercial Printing Enterprise: Addis Ababa, Ethiopia, 2005.

19. Lautze, S.; Aklilu, Y.; Raven-Roberts, A.; Young, H.; Kebede, G.; Leaning, J. Risk and Vulnerability in Ethiopia: Learning from the Past, Responding to the Present, Preparing for the Future; US Agency for International Development: Washington, DC, USA, 2003; Available online: https://fic.tufts.edu/assets/risk_ethiopia.pdf (accessed on 20 February 2017).

20. Federal Democratic Republic of Ethiopia (FDRE). Public Servants Pension Proclamation, Proclamation No. 345/2003; Federal Democratic Republic of Ethiopia: Addis Ababa, Ethiopia, 2003.

21. Dejene, M. Social Protection Policies, Institutions and Food Insecurity in Ethiopia. Ph.D. Thesis, Hawassa University, Hawassa, Ethiopia, 2019. Unpublished.

22. The New York Times. Ethiopia, a Nation of Farmers, Strains under Severe Drought. 18 October 2015. Available online: https:/www.nytimes.com/2015/10/19/world/africa/ethiopia-a-nation-of-farmers-strainsunder-severe-drought.html (accessed on 23 November 2015).

23. Ministry of Labour and Social Affairs (MoLSA). National Social Protection Policy of Ethiopia; Ministry of Labour and Social Affairs: Addis Ababa, Ethiopia, 2012.

24. Devereux, S.; Guenther, B. Agriculture and Social Protection in Ethiopia; Working Paper 8; Future Agricultures: Brighton, UK, 2009.

25. Reinert, E.S. How Rich Countries Got Rich and Why Poor Countries Stay Poor; Public Affairs: Washington, DC, USA, 2008

26. Anderson, C.; Alemu, M.; Stage, J. Impacts of the Productive Safety Net Program in Ethiopia on livestock and tree holdings of rural households. J. Dev. Econ. 2011, 94, 119-126. [CrossRef]

27. HLPE. Social Protection for food security: A report by The High Level Panel of Experts on Food Security and Nutrition. In HLPE Report 1; CFS: Rome, Italy, 2012; Available online: http://www.fao.org/fileadmin/user_upload/ hlpe/hlpe_documents/HLPE_Reports/HLPE-Report-4-Social_protection_for_food_security-June_2012.pdf (accessed on 25 December 2015).

28. Yishak, T.; Tassew, W. Beyond Food Security: Transforming the Productive Safety Net Program in Ethiopia for the Well-being of Children; Young Lives: Oxford, UK, 2012; ISBN 978-1-904427-95-7.

29. Giligan, D.; Hoddinott, J.; Alemayehu, S. The Impact of Ethiopia's Productive Safety Net Program and its Linkages. In International Food Policy Research Institute; IFPRI Discussion Paper, 00839; IFPRI: Washington, DC, USA, 2008; Available online: http://citeseerx.ist.psu.edu/viewdoc/download?doi=10.1.1.144.1491\&rep= rep1\&type $=$ pdf (accessed on 20 March 2015).

30. Devereux, S.; Sabates-Wheeler, R.; Tefera, M.; Taye, H. Ethiopia's Productive Safety Net Programme (PSNP): Trends in PSNP Transfers within Targeted Households; Institute of Development Studies and Indak International Pvt. L. C: Sussex, UK; Addis Ababa, Ethiopia, 2006.

31. Sabates-Wheeler, R.; Devereux, S. Cash Transfers and High Food Prices: Explaining Outcomes on Ethiopia's Productive Safety Net Program; Working Paper 004; Future Agricultures: Brighton, UK, 2010. 
32. Hoddinot, J.; Berhane, G.; Gilligan, D.; Kumar, N.; Tafesse, A. The Impact of Ethiopia's Productive Safety Net Program and Related Transfers on Agricultural Productivity. J. Afr. Econ. 2012, 21, 761-786. [CrossRef]

33. Pankhurst, A.; Rahmato, D. Introduction: Food Security, Safety Nets and Social Protection in Ethiopia. In Food Security, Safety Nets and Social Protection in Ethiopia; Dessalegn, R., Pankhurst, A., van Uffelen, J.-G., Eds.; Forum for Social Studies: Addis Ababa, Ethiopia, 2013; pp. xxi-xlv.

34. Van Uffelen, J.-G. Social Protection in Situations of Chronic Food Insecurity and Poverty: Lessons from Different Models and Implications for Ethiopia. In Food Security, Safety Nets and Social Protection in Ethiopia; Dessalegn, R., Pankhurst, A., van Uffelen, J.-G., Eds.; Forum for Social Studies: Addis Ababa, Ethiopia, 2013; pp. 147-174.

35. Aschale, D.S. The Importance of Labour for Food Security: Houesehold Experiences in Ebinat Woreda, Amhara Region. In Food Security, Safety Nets and Social Protection in Ethiopia; Dessalegn, R., Pankhurst, A., van Uffelen, J.-G., Eds.; Forum for Social Studies: Addis Ababa, Ethiopia, 2013; pp. 442-464.

36. Dejene, M.; Cochrane, L. Policy Coherence and Social Protection in Ethiopia: Ensuring No One Is Left Behind. Societies 2019, 9, 19. [CrossRef]

37. Cochrane, L.; Thornton, A. A Socio-Cultural Analysis of Smallholder Borrowing and Debt in Southern Ethiopia. J. Rural Stud. 2017, 49, 69-77. [CrossRef]

(C) 2020 by the authors. Licensee MDPI, Basel, Switzerland. This article is an open access article distributed under the terms and conditions of the Creative Commons Attribution (CC BY) license (http://creativecommons.org/licenses/by/4.0/). 